in vivo $31: 873-876(2017)$

doi:10.21873/invivo.11141

\title{
SCARB1 Gene Polymorphisms and HDL Subfractions in Coronary Artery Disease
}

\author{
HUSEYIN AYHAN ${ }^{1}$, UZAY GORMUS $^{2}$, SELIM ISBIR $^{3}$, SEDA GULEC YILMAZ $^{1}$ and TURGAY ISBIR ${ }^{4}$ \\ Departments of ${ }^{1}$ Molecular Medicine and ${ }^{4}$ Medical Biology, Yeditepe University, Istanbul, Turkey; \\ ${ }^{2}$ Department of Medical Genetics, Faculty of Medicine, Istinye University, Istanbul, Turkey; \\ ${ }^{3}$ Department of Cardiovascular Surgery, Marmara University, Istanbul, Turkey
}

\begin{abstract}
Background/Aim: Cardiovascular diseases are a leading cause of mortality and morbidity worldwide. Polymorphisms in the SCARBI gene are known to be related to plasma lipids. Patients and Methods: Real timepolymerase chain reaction (RT-PCR) was used for identification of SCARB1 polymorphisms and the Lipoprint Quantimetrix System was employed in identification of $H D L$ subfractions. Results: According to allelic distribution, in both groups SCARBI AA genotype led to a two-fold decrease in the risk of developing cardiovascular disease $(p=0.04)$, while the GA genotype increased the risk two-fold ( $p=0.03)$. According to the HDL subfraction analysis results, the $A A$ genotype had higher levels of big-sized HDL subfraction $(p=0.02)$. Conclusion: The SCARB1AA genotype decreased cardiovascular risk and carrying $G A$ genotype and $G$ allele increased the risk of CAD. AA genotype carriers had higher levels of big-sized HDL subfraction.
\end{abstract}

Cardiovascular diseases are a leading cause of mortality and morbidity worldwide (1). In cardiovascular diseases, mortality commonly occurs because of coronary artery disease (CAD) related to the damage of heart tissue (2). Considering HDL subfractions as being more important than HDL cholesterol, polyacrylamide gel electrophoresis was used and HDL was classified into 3 subclasses, big-sized HDL, intermediate-sized HDL, small-sized HDL; big sized and intermediate sized HDL subfractions were accepted as anti-atherogenic and the small

This article is freely accessible online.

Correspondence to: Prof. Turgay Isbir, Department of Medical Biology, Faculty of Medicine, Yeditepe University, Inonu Cad. 26 agustos Yerleskesi, 34755 Kayısdag1-Atasehir, Istanbul, Turkey. Tel: +905332823726/+90 2165780000-1263,e-mail: turgay.isbir@ yeditepe.edu.tr, tisbir@superonline.com

Key Words: Coronary artery disease, HDL subfractions, SCARB1, polymorphism. sized HDL subfraction group was accepted as atherogenic (3, 4). Some researches have suggested that there is a relationship between the variations of SCARBI gene and serum lipid profile $(5,6)$. In our study, we aimed to investigate the relationships between HDL subfractions and 2 variations of the SCARB1 gene in CAD cases.

\section{Materials and Methods}

Blood samples of patient $(n=52)$ and control $(n=58)$ groups were obtained from Marmara University, Department of Cardiovascular Surgery. Ethical Committee of Yeditepe University approved the study (2016-KAEK-1242, Decision No: 646, date: 29.06.2016). Control group subjects were chosen to have no risk of cardiovascular disease. Venous blood was obtained from each subject and conserved at $+4^{\circ}$ until DNA isolation. Isolation of DNA from blood samples was performed using the Invitrogen iPrep Purification Instrument and the iPrep PureLink gDNA Blood Kits (Invitrogen, Life Technologies, Carlsbad, CA, USA) according to the manufacture's protocol. To determine the DNA lconcentration, NanoDrop 2000 device (Thermo Scientific, Waltham, MA, USA) was used.

Genotyping. Genotyping of samples was carried out by Applied Biosystems Fast Real-Time polymerase chain reaction (RT-PCR) instrument and TaqMan Reagents primer-probe sets (Applied Biosystems, Foster City, CA, USA), specifically designed for $S C A R B 1$ gene rs 10846744 and SCARB1 rs 5888 polymorphisms. PCR reaction mixture contained $10 \mu \mathrm{l}$ X Genotyping Master Mix, $0.5 \mu 1$ 40X TaqMan Genotyping Assay (TaqMan Reagents; Applied Biosystems, Foster City, CA, USA), 8.5 $\mu$ l PCR grade water and $1 \mu \mathrm{l}$ of sample DNA. PCR conditions were $10 \mathrm{~min}$ of holding stage at $95^{\circ} \mathrm{C}$ and 40 cycles of $15 \mathrm{sec}$ denaturation at $92^{\circ} \mathrm{C}$ and $60 \mathrm{sec}$ of annealing/extension at $60^{\circ} \mathrm{C}$ as recommended by the supplier. Allelic discrimination was done using the software of 7500 Fast real-time PCR instrument.

Analysis of HDL subfractions. Analysis of HDL subfractions were performed by the Quantimetrix Lipoprint HDL System. Lipophilic dyes bind comparatively to the relative amount of cholesterol in each lipoprotein. In the first stage of electrophoresis, lipoprotein particles were condensed in a sharp band upon loading in the stacking gel. Lipoprotein particles then moved through the seperating gel matrix and resolved according to the particle sizes. 
Statistical analyses. Statistical analyses were performed using SPSS Ver 23 software (SPSS Inc, Chicago, IL, USA). Significant differences between groups were determined by Student's $t$-test, while demographics data were compared by $\chi^{2}$ and Fisher's exact tests. $p<0.05$ was accepted as statistically significant.

\section{Results}

The demographic characteristics of CAD and control groups were given in Table I. By comparison with diabetes diagnosis in both groups, $36.5 \%$ of patient and $19.0 \%$ of control groups had a diabetes diagnosis. The results demostrated that the diabetes risk was 2.46 fold higher for $\mathrm{CAD}$ (x2: 4.269, $p=0.03, \mathrm{OR}=2.46,95 \% \mathrm{CI}=1.035-5.847$ ). Furthermore, there was a significantly higher number of hypertensive individuals in the patient group and hypertension risk was increased 2.25 fold for CAD (x2: 4.084, $p=0.04, \mathrm{OR}=2.25,95 \% \mathrm{CI}=1.018-4.972$ ).

HDL subfractions of patient and control groups are shown in Table II. According to the HDL subfraction levels, in the control group, the mean of big sized HDL subfraction was higher compared to the patient group and the intermediate sized HDL was higher in the control group. Considering intermediate and big sized HDL in both groups, there were no significant differences. In the control group, the mean of the small sized HDL levels was $8.50 \pm 4.00 \mathrm{mg} / \mathrm{dl}$, whereas in the patient group the mean of the small sized HDL levels was $6.63 \pm 3.04 \mathrm{mg} / \mathrm{dl}$. Between the groups, small sized HDL was significantly different.

The genotypic and allelic frequencies of SCARBI rs10846744 polymorphism are given in Table III. The frequencies of CC, CG, GG were $5.8 \%, 34.6 \%, 38.6 \%$ in the patient group, whereas in the control group they were $6.9 \%$, $36.2 \%, 56.9 \%$. When the allelic frequencies were examined; the frequencies of $\mathrm{C}$ and $\mathrm{G}$ alleles were $21.81 \%$ and $72.72 \%$ in the patient group respectively. The frequencies of $\mathrm{C}$ and $\mathrm{G}$ alleles were $26.36 \%$ and $79.09 \%$ in the control group. There were no significant differences in the genotypic and allellic frequencies between both groups.

The genotypic and allelic frequencies of SCARBI gene rs5888 polymorphism are shown in Table III. In comparison between patient and control groups; the frequencies of AA, GA, GG were $17.30 \%, 57.7 \%, 25.0 \%$ in the patient group, and $34.5 \%, 37.9 \%$ and $27.6 \%$ in the control group repsectively. Carriers of the AA genotype were significantly higher in the control group and the risk was 2.51 fold reduced in CAD (x2: 4.16, $p=0.04, \quad \mathrm{OR}=0.398$, $95 \% \mathrm{CI}=0.162-0.978)$. Analyses also showed that the GA genotype carriers had a 2.23 -fold increased risk for CAD (x2: 4.296, $p=0.03, \quad \mathrm{OR}=2.23, \quad 95 \% \mathrm{CI}=1.039-4.791)$. Examining the allelic frequencies demonstrated that the frequencies of $\mathrm{A}$ and $\mathrm{G}$ alleles were $43.63 \%$ and $50.90 \%$ in the patient group, and the frequencies of the A allele and $\mathrm{G}$ allele were $56.36 \%, 49.09 \%$ in the control group. Carrying
Table I. The demographic characteristics of patient and control groups.

\begin{tabular}{|c|c|c|c|}
\hline Parameter & $\begin{array}{c}\text { Control } \\
(\mathrm{n}=58)\end{array}$ & $\begin{array}{l}\text { Patient } \\
(\mathrm{n}=52)\end{array}$ & $p$-Value \\
\hline Age (years), mean \pm SD & $57.07 \pm 10.75$ & $59.96 \pm 6.816$ & 0.09 \\
\hline Body Surface Area $\left(\mathrm{m}^{2}\right)$ & $1.87 \pm 0.18$ & $1.89 \pm 0.18$ & 0.55 \\
\hline \multicolumn{4}{|l|}{ Body mass index $(\mathrm{kg} / \mathrm{m})$, } \\
\hline \multicolumn{4}{|l|}{ Family History } \\
\hline Yes & $20.7 \%(12)$ & $34.6 \%(18)$ & 0.10 \\
\hline No & $79.3 \%(46)$ & $65.4 \%(34)$ & \\
\hline \multicolumn{4}{|l|}{ Smoking } \\
\hline Yes & $36.2 \%(21)$ & $53.8 \%(28)$ & 0.06 \\
\hline No & $63.8 \%(37)$ & $46,2 \%(24)$ & \\
\hline \multicolumn{4}{|l|}{ Hypertension } \\
\hline Yes & $27.6 \%(16)$ & $46.2 \%(24)$ & $0.04 *$ \\
\hline No & $72.4 \%(42)$ & $53.8 \%(28)$ & \\
\hline \multicolumn{4}{|l|}{ Type 2 Diabetes Mellitus } \\
\hline Yes & $19 \%(11)$ & $36.5 \%(19)$ & $0.03 *$ \\
\hline No & $81.0 \%(47)$ & $63.5 \%(33)$ & \\
\hline
\end{tabular}

$\mathrm{n}$ : Number of individuals; values are given as mean \pm standard deviation; *statistically significant difference.

Table II. HDL subfractions of patient and control groups.

\begin{tabular}{lccc}
\hline & $\begin{array}{c}\text { Control } \\
(\mathrm{n}=58)\end{array}$ & $\begin{array}{c}\text { Patient } \\
(\mathrm{n}=52)\end{array}$ & $p$-Value \\
\hline Big Sized HDL (mg/dl) & $12.75 \pm 5.68$ & $11.69 \pm 6.80$ & 0.39 \\
Intermediate Sized HDL (mg/dl) & $21.25 \pm 4.79$ & $21.33 \pm 5.04$ & 0.93 \\
Small Sized HDL (mg/dl) & $8.50 \pm 4,00$ & $6.63 \pm 3.04$ & $0.01^{*}$ \\
\hline
\end{tabular}

$\mathrm{n}$ : Number of individuals; values are given as mean \pm standard deviation; *statistically significant difference.

the $\mathrm{G}$ allele was observed to increase the risk of CAD ( $\mathrm{x} 2$ : 4.166, $p=0.04, \mathrm{OR}=2.515,95 \% \mathrm{CI}=1.023-6.183$ ).

Distribution of HDL subfractions and genotypic distribution of the SCARB $1 \mathrm{G}>\mathrm{A}$ polymorphism are shown comparatively in Table IV. The mean of big sized HDL level in patients with the AA genotype was $14.48 \pm 9.01 \mathrm{mg} / \mathrm{dl}, 11.94 \pm 5.01 \mathrm{mg} / \mathrm{dl}$ with the GA genotype, and $10.30 \pm 3.58 \mathrm{mg} / \mathrm{dl}$ with the GG genotype. Big sized HDL in patients with the AA genotype was significantly higher than with the other genotypes.

\section{Discussion}

Recent studies, have suggested that total plasma lipid levels are not enough as determining factors for CAD and emphasized that lipoprotein subfractions should also be studied. Nearly half the individuals with CAD had normal total cholesterol levels and therefore it was thought that the 
Table III. rs5888 and rs10846744 genotypic and allelic frequencies in patients with CAD and the control group.

\begin{tabular}{|c|c|c|c|c|c|}
\hline & Control $(n=58)$ & Patient $(n=52)$ & $p$-Value & Odds ratio $(\mathrm{OR})$ & $95 \%$ confidence interval $(\mathrm{CI})$ \\
\hline Genotype Scarb1 G>A & $\%(\mathrm{n})$ & $\%(\mathrm{n})$ & & & \\
\hline $\mathrm{AA}$ & $34.5 \%(20)$ & $17.3 \%(9)$ & $0.04^{*}$ & 0.398 & $0.162-0.978$ \\
\hline GA & $37.9 \%(22)$ & $57.7 \%(30)$ & $0.03 *$ & 2.231 & $1.039-4.791$ \\
\hline \multirow[t]{2}{*}{ GG } & $27.6 \%(16)$ & $25.0 \%(13)$ & 0.75 & 0.875 & $0.373-2.051$ \\
\hline & Allelic count & Allelic count & & & \\
\hline A & $56.36 \%(62)$ & $43.63 \%(48)$ & 0.75 & 1.143 & $0.488-2.679$ \\
\hline G & $49.09 \%(54)$ & $50.90 \%(56)$ & $0.04 *$ & 2.515 & $1.023-6.183$ \\
\hline \multicolumn{6}{|l|}{ Genotype } \\
\hline \multicolumn{6}{|l|}{ Scarb1 $C>G$} \\
\hline $\mathrm{CC}$ & $6.9 \%(4)$ & $5.8 \%(3)$ & 0.80 & 0.827 & $0.176-3.879$ \\
\hline CG & $36.2 \%(21)$ & $34.6 \%(18)$ & 0.86 & 0.933 & $0.426-2.041$ \\
\hline \multirow[t]{2}{*}{ GG } & $56.9 \%(33)$ & $59.6 \%(31)$ & 0.77 & 1.118 & $0.523-2.390$ \\
\hline & Allelic count & Allelic count & & & \\
\hline $\mathrm{C}$ & $26.36 \%(29)$ & $21.81 \%(24)$ & 0.77 & 0.894 & $0.418-1.911$ \\
\hline G & $79.09 \%(87)$ & $72.72 \%(80)$ & 0.80 & 1.210 & $0.256-5.676$ \\
\hline
\end{tabular}

$\mathrm{n}$ : Number of individuals; *statistically significant difference.

qualitative properties such as HDL particle size should gain importance rather than the quantitative properties (7).

Using the Lipoprint System, based on the polyacrylamide gel electrophoresis principle, the HDL subfractions were classified as big-sized HDL, intermediate-sized HDL and small-sized HDL. It has been suggested that big-sized HDL and intermediate-sized HDL have protective properties and small HDL had atherogenic properties.

Hamidreze et al. (2016) investigated the relationships between premature $\mathrm{CAD}$ and $S C A R B 1 \mathrm{C}>\mathrm{T}$ variation at cDNA position 1050 base position on exon 8 (rs 5888) and their results showed smilarities with our study. They found that the $\mathrm{T}$ allele was 1.3 fold increased compared to the $\mathrm{C}$ allele in CAD cases. TT genotype increased the risk of CAD 1.7 times. TT genotype increased the the risk of CAD in women more than in men (8). Dong-Fen-Wu et al. investigated the effects of SCARBI C $>\mathrm{T}$ polymorphism in CAD, but opposite to our findings, they found that the TT genotype was higher in the patient group and revealed that the TT genotype increased the risk of CAD. TT genotype carriers had lower HDL levels (9). Jihene et al. indicated that in the control group, TT genotype carriers had higher HDL levels and a decreased risk of CAD (10).

Hypertension is a predisposing factor for atherosclerosis by causing a continuous injury in the endothelium. Advanced atherosclerosis contributes to plaque growth. It has been observed that hypertension increases stroke risk by 2 times and heart attack risk by 3 times compared to cases with a normal blood pressure. Yan et al. investigated the relationship between hypertension and HDL subfractions in a study of 953 hypertensive patients. It was determined that the large HDL
Table IV. Distribution of HDL subfractions dependent genotype in the SCARB1 G>A polymorphism.

\begin{tabular}{lcccc}
\hline & AA & GA & GG & $p$-Value \\
\hline Big Sized HDL & $14.48 \pm 9.01$ & $11.94 \pm 5.01$ & $10.30 \pm 3.58$ & $0.02^{*}$ \\
Intermediate HDL & $21.97 \pm 5.77$ & $21.46 \pm 4.10$ & $20.26 \pm 5.18$ & 0.40 \\
Small Sized HDL & $8.31 \pm 4.54$ & $7.23 \pm 3.25$ & $7.37 \pm 3.28$ & 0.19 \\
\hline
\end{tabular}

$\mathrm{n}$ : Number of individuals; values are given as mean \pm standard deviation; *statistically significant difference.

subfraction levels in hypertensive patients was lower and the small HDL subfraction of the same patients was higher compared to their equivalents. While the big-sized HDL subfractions result in a low risk of hypertension, small HDL subfractions increase hypertension risk. Big sized HDL levels have not been associated with any predisposition to CAD in patients with hypertension. Besides, it was observed that small-sized HDL subfractions were lower in patients whose blood pressure was successfully controlled (11).

Rui-Xia et al. studied the relationships between HDL subfractions and CAD and observed that coronary artery patients had decreased levels of HDL-cholesterol, especially the big-sized HDL. In our study, we found that small-sized HDL level was higher in the control group. And there were no significant differences of intermediate HDL between the two groups. We also observed that there was an inverse relationship between the level of big-sized HDL subfractions and CAD. The risk of development of CAD increases with 
the level of small HDL subfractions; in the patients with a high ratio of small HDL subfractions, there is a risk of CAD development (12).

Georg et al. found an inverse relationship between big sized HDL levels and the patients with myocardial infarction and also there was a direct relationship between intermediate-sized and small-sized HDL levels and myocardial infarctions (13).

Rui-Xia et al. (2015) found that coronary artery patients had lower levels of big-sized HDL and concluded that smallsized HDL levels were related to CAD (14). Jian-Jun et al. (2016) observed that big-sized HDL levels were inversely correlated with the risk of cardiovascular diseases (15).

In another study byRui-Xia et al. it was found that bigand intermediate-sized HDL subfractions levels were lower in patients compared to healthy people. Intermediate- and small-sized HDL were found to be associated with the risk of CAD development (16).

\section{Conclusion}

In the single nucleotide polymorphism (SNP) of rs5888, a"G" to "A" substitution at amino acid 350 in exon 8 of the $S C A R B 1$ gene, the AA genotype decreases cardiovascular risk two times $(p=0.04)$, and the GA genotype increases two times the same risk $(p=0.03)$. According to the HDL subfraction analysis results, AA genotype carriers had higher levels of big-sized HDL subfractions that are known to be antiatherogenic $(p=0.02)$.

\section{Conflicts of Interest}

The Authors declare no conflicts of interest in regard to this study

\section{References}

1 Kingsburry KJ and Bondy G: Understanding the essentials of blood lipid metabolism. Prog Cardiovasc Nurs 18(1): 13-18, 2003.

2 Wang Y, Wang L, Liu X, Zhang Y, Yu L, Zhang F, Liu L, Cai J, Yang $X$ and Wang $X$ : Genetic variants associated with myocardial infarction and the risk factors in Chinese population. PLoS One 9(1): e86332, 2014.

3 Pirillo A, Norata GD and Catapano AL: High-density lipoprotein subfractions-what the clinicians need to know. Cardiology 124(2): 116-125, 2013.

4 Acton S, Rigotti A, Landschulz KT, Xu S, Hobbs HH and Krieger M: Identification of scavenger receptor SR-BI as a high density lipoprotein receptor. Science 271: 518-520, 1996.

5 Krieger M: Charting the fate of the 'good cholesterol': identification and characterization of the high-density lipoprotein receptor SR-BI. Annu Rev Biochem 68: 523-558, 1999.
6 Williams DL, Connelly MA, Temel RE, Swarnakar S, Philips MC, Llera-Moya M and Rothblat GH: Scavenger receptor BI (SR-BI) and cholesterol trafficking. Curr Opin Lipidol 10: 329339, 1999.

7 Hegele RA: The genetic basis of atherosclerosis. Int J Clin Lab Res 27: 2-13, 1997.

8 Goodarzynejad $\mathrm{H}$, Boroumand $\mathrm{M}$, Behmanesh $\mathrm{M}$, Ziaee $\mathrm{S}$ and Jalali A: The rs5888 single nucleotide polymorphism in scavenger receptor class B type 1 (SCARB1) gene and the risk of premature coronary artery disease: a case-control study. Lipids Health Dis 15(1): 1-9, 2016.

9 Wu DF, Yin RX, Cao XL, Chen WX, Aung LHH, Wang W, Huang KK, Huang P, Zeng XN and Wu J: Scavenger receptor class B Type 1 gene rs5888 single nucleotide polymorphism and the risk of coronary artery disease and 1schemic stroke: A CaseControl Study. Int J Med Sci 10(12): 1771-1777, 2013.

10 Rejeb J, Omezzine A, Boumaiza I, Rebhi L, Kacem S, Rejeb NB, Nabli N, Abdelaziz AB, Boughzala E and Bouslama A: Association of three polymorphisms of scavenger receptor class BI gene (exon8, exon1, intron5) with coronary stenosis in a coronary Tunisian population. Gene 511: 383-388, 2012.

11 Zhang Y, Li S, Xu RX, Guo YL, Wu NQ, Zhu CG, Gao Y, Dong Q, Liu G, Sun J and Li JJ: Distribution of high-density lipoprotein subfractions and hypertensive status. Medicine 94(43): e1912, 2015.

12 Xu RX, Li S, Li XL, Zhang Y, Guo YL, Zhu CG, Wu NQ, Qing P, Sun J, Dong Q and Li JJ: High-density lipoprotein subfractions in relation with the severity of coronary artery disease: A Gensini score assessment. J Clin Lipidol 9: 26-34, 2015.

13 Goliasch G, Oravec S, Blessberger H, Dostal E, Hoke M, Wojta J, Schillinger M, Huber K, Maurer G and Wiesbauer F: Relative importance of different lipid risk factors for the development of myocardial infarction at a very young age $(<40$ years of age). Eur J Clin Invest 42(6): 631-636, 2011.

14 Xu RX, Zhang Y, Ye P, Chen H, Li YF, Hua Q, Guo YL, Li XL, Li S, Dong Q, Liu G and Li JJ: Analysis of lipoprotein subfractions in chinese han patients with stable coronary artery disease. Heart, Lung Circ 24(12): 1203-1210, 2015.

15 Li JJ, Zhang Y, Li S, Cui CJ, Zhu CG, Guo YL, Wu NQ, Xu RX, Liu G, Dong Q and Sun J: Large HDL subfraction but not HDL$\mathrm{C}$ is closely linked with risk factors, coronary severity and outcomes in a cohort of nontreated patients with stable coronary artery disease. Medicine 95(4): e2600, 2016.

16 Xu RX, Li S, Guo YL, Liu J, Sun J, Zhu CG and Jiang LX: The correlation between HDL particle size and stable coronary heart disease. Lipid Cardiovasc Res 01(1): 37-43, 2015.
Received May 30, 2017

Revised June 22, 2017

Accepted June 23, 2017 